\title{
The effect of birth weight on hospitalizations and sickness absences: a longitudinal study of Swedish siblings
}

\author{
Jonas Helgertz ${ }^{1,2,3}$ (D) Anton Nilsson ${ }^{1,4,5}$
}

Received: 11 October 2016 / Accepted: 10 May 2018/Published online: 29 May 2018

(C) The Author(s) 2018

\begin{abstract}
We examine the effect of birth weight on health throughout childhood, adolescence, and early adulthood, focusing on two health outcomes: all-cause and cause-specific hospitalizations and sickness absences. The outcomes are important, not only from a health perspective but also from a labor market perspective, as the inability to fully participate in the labor force due to impaired health is known to have important long-term consequences. Our analysis focuses on differences between siblings, using full-population Swedish register data on cohorts born between 1973 and 1994. The relationship between birth weight and health is strongest during infancy, after which it weakens throughout childhood and adolescence. In adulthood, a stronger relationship again appears, suggesting a U-shaped relationship over the examined part of the life course. During childhood and adolescence, birth weight influences all examined disease types with the exception of cancers, with nontrivial effect sizes in relative terms. During adulthood, morbidity due to mental diseases dominates, primarily through conditions with early-age origins. Consequently, we provide new evidence that
\end{abstract}

Responsible editor: Erdal Tekin

Jonas Helgertz

helgertz@umn.edu

Anton Nilsson

anton.nilsson@nek.lu.se

1 Centre for Economic Demography, Lund University, P.O. Box 7083, SE-220 07 Lund, Sweden

2 Department of Economic History, Lund University, P.O. Box 7083, SE-220 07 Lund, Sweden

3 Minnesota Population Center, University of Minnesota, 225 19th Ave S \#50, Minneapolis, MN 55455, USA

4 Division of Occupational and Environmental Medicine, Lund University, Scheelevägen 8, Building 406, SE-223 81 Lund, Sweden

5 Department of Economics and Business Economics, Aarhus University, Fuglesangs Allé 4, 8210 Aarhus V, Denmark 
birth weight matters for both short- and long-term health outcomes and that it is of a dynamic nature in terms of its magnitude and which disease types are affected. Lastly, our results remain robust to a range of sensitivity analyses, including nonlinear specifications of birth weight, and to estimations based on a sample of same-sex twin pairs, allowing us to further reduce the influence of genes.

Keywords Early life $\cdot$ Birth weight $\cdot$ Hospitalizations $\cdot$ Sickness absence $\cdot$ Siblings $\cdot$ Twins

JEL classification $\mathrm{I} 10 \cdot \mathrm{I} 14 \cdot \mathrm{I} 18$

\section{Introduction}

Substantial evidence suggests that conditions in utero have important and longlasting effects on health as well as on socioeconomic outcomes. Frequently, the so-called Barker hypothesis has been a point of departure, according to which fetal growth restriction programs the individual to experience an increased likelihood of adult disease (e.g., Barker 1990; 1995). Since then, a large number of researchers have documented associations between lower birth weight and a range of health problems later in life. For a substantial amount of existing studies, it is, however, unclear whether associations reflect causality or whether the hypotheses tested reflect explicit physiological mechanisms between in utero and later-life health.

Studies in economics have often used exogenous shocks or within-family comparisons to try to disentangle the causal effects of prenatal circumstances (see for example Almond and Currie 2011) on later-life health. Some studies (e.g., Almond et al. 2005; Almond 2006; Black et al. 2007) have documented effects on outcomes such infant mortality or adult self-reported disability, whereas other studies (e.g., Oreopoulos et al. 2008; Almond et al. 2009; Field et al. 2009; Royer 2009) find no or little evidence of effects on a range of outcomes, such as self-reported days of illness in childhood or adolescence, hypertension, or diabetes.

In this study, we provide new evidence on the relationship between birth weight and health outcomes throughout childhood and into early adulthood. Using full-population Swedish register data on individuals born between 1973 and 1994, followed until 2011, our analysis exploits differences between siblings and twins, aiming to better allow for causal inference. Our analysis considers both inpatient visits and sickness absences, examining how the effect changes from birth until adulthood (individuals who are in their 30s). Furthermore, by exploiting data on specific diagnoses, we contribute to the literature not only by studying the total number of days in care but also by studying whether the individual was diagnosed with different types of diseases. To our knowledge, this is one of the first studies examining the effect of birth weight on days of sickness absence in adulthood. Due to its importance, both to the individual's ability to successfully pursue a labor market career and to a country's public finances (in particular for generous welfare states, like Sweden), this outcome represents an important complement to hospital stays. 


\section{Background}

\subsection{Physiological mechanisms}

Relationships between conditions experienced during the fetal stage and postnatal health and well-being have been documented for at least half a century. Despite the breadth of existing research, the empirical literature examining the relationship from a more mechanistic perspective emerges as considerably smaller and to a substantial extent speculative. In the absence of precise information on the nature and timing of the fetal insult, which is almost consistently the case in studies using observational data on humans, it will remain a challenge to pinpoint the physiological mechanism linking insult and disease. If the ambition, however, is to better understand the nature of the relationship, it is arguably of importance to base hypothesized relationships on theoretically plausible links between early-life insults and specific types of health conditions. In this paper, we therefore focus on five types of diseases which all have been highlighted as linked with early-life insults through specific pathways.

\subsubsection{Endocrine and cardiovascular conditions}

Generally considering as the outcome most strongly associated with fetal disturbances, a large literature following Barker and colleagues' seminal articles (Barker et al., 1889, $1990,1995)$ has demonstrated the link between indicators of in utero adversity, most commonly through birth weight and cardiovascular disease. When examining cardiovascular conditions, it makes sense to also consider endocrine disease, due to their strong degree of interrelatedness, since diseases to the endocrine system such as diabetes or other conditions manifested through overweight or obesity are strong predictors of the onset of heart disease (e.g., Grundy et al., 2000; Eckel 1997). Mechanistically, explanations to why the intrauterine environment predisposes the onset of later-life endocrine and cardiovascular disease essentially originate from the earliest literature within the field and the thrifty phenotype hypothesis (Hales and Barker 1992). This hypothesis proposes a reprogramming of the endocrine-metabolic status of the fetus as a response to exposure to-for example-fetal malnutrition. Survival in the short term is promoted by an overactivation of the HPA axis and, as a result, a permanent increase in cortisol levels (Kanaka-Gantenbein 2010). This process is hypothesized to result in - for example - insulin resistance, impaired functioning of the pancreas, predisposition of the individual to dyslipidemia, arterial hypertension, and type 2 diabetes (e.g., Oken and Gillman 2003; Kanaka-Gantenbein 2010; Padmanabhan et al. 2016).

\subsubsection{Mental conditions}

Empirical research which supports a link between observable indicators of fetal growth, such as birth weight, and mental health has grown to include overall cognitive functioning, behavioral problems, and personality disorders as well as the ability to cope with stress (Schlotz and Phillips 2009). Mechanistically, a diversity of fetal insults - from maternal smoking and diet to psychosocial stress- have been proposed to affect different aspects of in utero brain development, linked to the postnatal onset of 
mental conditions. In terms of how the fetal environment affects the development of the brain, research has shown that being born small for gestational length is associated with both brain volume (Martinussen et al. 2005) and the functioning of the frontal lobe (Geva et al. 2006). Related to this, Schlotz et al. (2008) showed that fetal head growth is an important predictor of hyperactivity and inattention. Indeed, while brain volume per se has been shown to be linked to cognitive ability, in terms of the consequences of early-life insults for mental health, existing knowledge would instead point towards how insults that also alter the brain growth result in permanent chemical imbalances. Several conditions, including the ability to deal with stress, anxiety, and depression, are linked to such chemical imbalances in the central nervous system, through a permanent change in how stimuli are interpreted and responded to (McEwen 2003). Lastly, the mother's exposure to stress during pregnancy can lead to numerous neurodevelopmental changes, including structural changes in areas such as the hippocampus and amygdala, especially important for cognitive and emotional functions.

\subsubsection{Respiratory conditions}

Fetal disturbances, measured through birth weight, have been shown to be associated with a range of respiratory conditions, in childhood as well as in adulthood, including but not limited to asthma and chronic obstructive airway disease (Duijts 2012). Mechanistically, the rationale for the fetal origins of various respiratory conditions is linked to a significant part of the formation of the lungs as well as how they are programmed to continue to develop which occurs prior to birth. Existing research has highlighted the relevance of both the timing and the nature of the insult in understanding how the developmental trajectory of the lungs is changed. During the initial embryonic phase, from about 22 days after fertilization, substantial changes in the lung structure are likely to be due to disruptions to the rapid process of cellular differentiation and lung formation that dominates during this phase (Harding and Maritz 2012). These processes are very sensitive, and exposure to pollutants such as tobacco has been suggested to be responsible for various disruptions to the development of the lungs. During this phase, exposure to insults may also disrupt the developmental trajectory of the enzymes that will become responsible for lung cell metabolism and for protecting the lung against harmful compounds during postnatal life. For example, whereas growth restriction has been shown to influence the lung architecture, other insultsfrom exposure to toxins or improper maternal diet - may result in epigenetic changes, thus manipulating how DNA is expressed, while leaving the actual DNA sequence unchanged. In particular, the latter has been suggested as possibly programming the onset of later disease - or programming an altered developmental trajectory of certain functions of the lung (Duijts 2012; Harding and Maritz 2012).

\subsubsection{Cancer}

The most commonly proposed pathway through which the prenatal environment influences the development of cancers subsequent to birth is epigenetic reprogramming. Indeed, up to half of all childhood cancers are believed to have fetal origins (Marshall et al. 2014). Research has suggested such changes to be resulting from maternal diet and other environmental factors. One central proposed mechanism behind the process 
by which normal cells are transformed into cancer cells is labeled the cancer stem cell (CSC) hypothesis. According to this, a subset of cancer stem cells are created through epigenetic reprogramming (Shukla and Meeran 2014), responsible for both tumor growth and metastatic spread (Ajani et al. 2015; Clarke 2005). While still a far from a fully understood area, CSC markers have been found in a range of different tumor types, including leukemia and brain, lung, liver, and pancreatic cancer (Ajani et al. 2015). The fetal origins of leukemia (Wiemels et al. 1999) and breast cancer (HilakiviClarke and de Assis 2006) have also been supported by other research, albeit not explicitly focusing on the role of cancer stem cells.

\subsection{Previous research}

A plethora of epidemiological studies has demonstrated associations between measures of fetal and later-life health. In general, it may be questioned how credible these studies are from a causal perspective, as the large majority link future outcomes to measures of early-life health, without adjusting for the broad range of factors such as the mother's biological constraints, socioeconomic status, exposure to infections, and genetics, which may influence fetal health as well as later outcomes.

Exceptions to the studies of a correlational nature are represented by studies exploiting variation within siblings or twins, as well as exposure to exogenous health shocks during the fetal stage, primarily emerging from the economics literature. Examples of the latter include studies examining the outcomes of individuals exposed to environmental insults, such as influenza pandemics. The perhaps most well-known example is represented by the 1918-1919 Spanish flu pandemic, examined in a range of settings, including the USA (Almond 2006; Myrskylä et al. 2013) and Sweden (Karlsson et al. 2014). The results of Almond (2006) suggest a negative long-term influence on health outcomes in older ages, and the latter was largely replicated by Myrskylä et al. (2013). Other environmental shocks that have been examined include the 1957 Asian flu (Kelly, 2011), the 1944-1945 Dutch hunger winter (e.g., Rooij et al. 2010; Scholte et al. 2012), the 1959-1961 Chinese famine (Chen and Zhou 2007; Almond et al. 2010), and the 1986 Chernobyl disaster (Almond et al. 2009). The iodine supplementation program implemented in Tanzania in the 1990s (Field et al. 2009) represents one positive shock, however with no effects on self-reported health measured at ages 10-13.

Another approach used to more credibly assess the effect of birth weight relies on within-sibling or within-twin variation, using fixed effects to cancel out the influence of all characteristics shared by siblings and twins, respectively. Such factors include genes, parenting style, lifetime wealth, and biological constraints of the mother. Both approaches have their advantages and shortcomings, with siblings allowing for larger study samples of individuals with more "normal" fetal experiences as well as with greater external validity, but with fewer shared characteristics. Instead, studies of monozygotic twins are appealing since these are (almost) identical genetically and most often share the same placenta but are on the other hand also characterized by a fetal environment that differs quite substantially from that of singletons, as well as small study samples. Existing twin studies represent a multitude of contexts, examining the influence of differences in birth weight within twin pairs on a range of health outcomes, such as blood pressure and the incidence of specific conditions such as 
ischemic heart disease (IHD). Results have often been insignificant (Huxley et al. 2002; Huxley et al. 2007), although this may be because twin samples are generally small and thus the power to detect effects is relatively low. There are also studies considering other outcomes within twin pairs, such as diabetes, asthma, and ADHD, in some cases reporting significant effects (e.g., Poulsen et al. 1997; Örtqvist et al. 2009; Kindlund et al. 2010; Pettersson et al., 2015).

Studies in economics have reported that birth weight differences within twin pairs are related to infant and child mortality (Almond et al. 2005; Black et al. 2007; Conley and Strully 2012; Oreopoulos et al. 2008; Royer 2009) as well as BMI and height (Black et al. 2007; Saldarriaga 2015). There is also evidence of an effect on education (Black et al. 2007; Oreopoulos et al. 2008; Royer 2009; Xie et al. 2016) and labor market outcomes (Black et al. 2007; Oreopoulos et al. 2008). While most of these studies benefit from using comprehensive registry-based data and sound empirical strategies for achieving causal estimates, it is not always clear how to interpret the results. It is, for example, far from clear how a certain effect on an individual's height may be interpreted in terms of health problems, and at what ages. Moreover, studies have generally not been able to follow individuals and compare outcomes across ages. Bharadwaj et al. (2018) is an exception to this as they follow individuals' incomes and health outcomes from age 30 and up. In our study, we follow health across individuals' lives, but instead consider the first few decades of an individual's life-hospitalizations from age 0 to age 30 , and sickness absence in young adulthood.

\section{Data and method}

\subsection{Data}

The data used in this paper comes from the Swedish Interdisciplinary Panel (SIP) database, administered at the Centre for Economic Demography, Lund University. The database comprises several population-wide registers which have been linked together through personal identifiers. Data is available for all individuals born in Sweden between 1973 and 1995, including their parents and siblings, followed until 2012. We examine the individual's health from birth until the early stages of adulthood, with the oldest observations pertaining to individuals of age 38 . Out of necessity due to data availability, we divide the sample into a child and an adult sample. The childhood sample consists of the entire population born between 1973 and 1994, examined from birth until age 17. The adulthood sample consists of the entire population born between 1973 and 1981.

Information on birth weight is obtained from the Medical Birth Register, operationalized as the logarithm of birth weight. For the outcome variables, we rely on the data on hospital admissions and discharges, also exploiting information on the underlying diagnoses. Since 1987, this register covers the entire country, but about half of all counties (the administrative regions in Sweden responsible for health care) reported to the register already in 1973. For the adulthood sample, we also analyze data on spells of sickness absence and disability pension, both referred to as sickness absence in the analysis. Since regulations surrounding the eligibility for sickness and disability benefits have changed over time, we, however, focus on outcomes observed in the most 
recent year available in these data, 2011, when the adulthood sample is between 29 and 38 years of age. Similar to the hospital data, we have information on the start and end dates of each spell, as well as on the underlying medical diagnoses. One caveat with the data on leaves due to sickness and disability is that only spells exceeding 14 days are observable, due to the data-providing agency only taking responsibility for the payment of benefits from this point. As a result, if individuals with poor birth outcomes have a larger tendency to experience not only longer but also shorter sickness absence spells, the estimates we produce may be viewed as lower bounds of the overall effects.

The analysis focuses on several different outcomes, measuring various aspects of an individual's health. Data on hospitalization is used to measure both overall and causespecific morbidities, in different age groups. More specifically, we examine both the annual number of days of hospitalization and whether an individual experienced any hospitalization spell. Hospitalization is examined between ages 0 and 17 for the childhood sample and between ages 18 and 30 for the adulthood sample. Sickness absence is analyzed in a similar fashion, examining both the duration of absence spells and whether an individual experienced any absence, as well as examining all-cause and cause-specific absences. We exclude hospital visits or absences related to pregnancy since our interest lies in health and not in the effect of birth weight on fertility.

We proceed to distinguish between major diagnosis types, which we can plausibly link to the fetal growth process. We differentiate between cancers; circulatory conditions; respiratory conditions; endocrine, nutritional, and metabolic conditions; and mental conditions. Since much of the effect turns out to be driven by mental problems and since these problems can take many forms, we further distinguish between causes within this group. More specifically, we separately examine morbidity due to psychotic conditions and personality disorders (F0, F2, and F6 in the ICD10 classification), behavioral syndromes ${ }^{1}$ (F5), mood- and anxiety/stress-related disorders (F3-F4), disorders of development with early onset (F7-F9), and mental and behavioral disorders due to psychoactive substance use (F1). During infancy, we also consider inpatient visits due to perinatal problems. While there is no specific threshold, these hospitalizations are often a direct consequence of a relatively low birth weight and they may as such be more reflective of hospitals' expectations of health problems rather than of actual health.

When examining child outcomes, we focus on outcomes during infancy (age 0), at age 1, at ages 2-5, at ages 6-12, and at ages 13-17, respectively. After necessary sample selection criteria have been applied, ${ }^{2}$ the sibling sample, consisting of native Swedes born between 1973 and 1994, amounts to 1,060,072 individuals observed from birth. Our twin sample, where we only include complete twin pairs, includes 27,246 individuals. Naturally, when considering outcomes at ages later than 0 , the study samples are slightly reduced, as only those who survived up to the beginning of the age interval of interest are examined.

The adult sample is represented by native Swedes born between 1973 and 1981 and observed by the age of 18 , which amounts to 371,623 individuals after the sample selection criteria have been applied. The samples shrink somewhat further when

\footnotetext{
${ }^{1}$ For hospitalizations, this category is almost entirely dominated by eating disorders ( $~ 90 \%$ of cases).

${ }^{2}$ Individuals with missing information on birth weight or gestational length are excluded (1\%). In addition, we exclude individuals residing in counties not reporting hospitalization spells $(23 \%)$ as well as individuals with congenital malformations $(5 \%)$ and with mothers without information on education $(1 \%)$.
} 
considering sickness absences, as we only include those surviving up to the year 2011. Table 1 shows the descriptive statistics for the childhood and Table 2 for the adult outcome samples. Our estimated models consistently include fixed effects for gestational length,

Table 1 Descriptive statistics for childhood/adolescence samples

\begin{tabular}{|c|c|c|}
\hline & Siblings & Twins \\
\hline Birth year & $1985.919(5.566)$ & $1986.720(5.798)$ \\
\hline Birth parity & $1.938(0.961)$ & $1.944(1.000)$ \\
\hline Gestational days & $279.098(12.435)$ & $260.106(17.112)$ \\
\hline Log birth weight & $8.154(0.174)$ & $7.851(0.233)$ \\
\hline \multicolumn{3}{|l|}{ Hospital days/year } \\
\hline Age 0 & $1.427(7.045)$ & $5.879(15.284)$ \\
\hline Age 1 & $0.538(4.026)$ & $0.675(5.559)$ \\
\hline Ages 2-5 & $0.280(2.465)$ & $0.285(1.809)$ \\
\hline Ages 6-12 & $0.187(1.745)$ & $0.170(1.112)$ \\
\hline Ages 13-17 & $0.211(2.255)$ & $0.225(2.971)$ \\
\hline \multicolumn{3}{|l|}{ Specific diagnoses $(0 / 1)$} \\
\hline Perinatal (only age 0 ) & 0.046 & 0.212 \\
\hline Respiratory & 0.184 & 0.196 \\
\hline Neoplasms & 0.009 & 0.009 \\
\hline Endocrine, etc. & 0.019 & 0.022 \\
\hline Circulatory & 0.007 & 0.008 \\
\hline Mental & 0.029 & 0.031 \\
\hline Mental, F0/F2/F6 (ICD10) & 0.001 & 0.001 \\
\hline Mental, F1 & 0.011 & 0.010 \\
\hline Mental, F3/F4 & 0.007 & 0.006 \\
\hline Mental, F5 & 0.007 & 0.009 \\
\hline Mental, F7/F8/F9 & 0.008 & 0.010 \\
\hline \multicolumn{3}{|l|}{ Specific diagnoses, days/year } \\
\hline Perinatal & $0.596(4.864)$ & $4.387(12.546)$ \\
\hline Respiratory & $0.057(0.965)$ & $0.078(1.028)$ \\
\hline Neoplasms & $0.025(0.878)$ & $0.017(0.454)$ \\
\hline Endocrine, etc. & $0.019(0.638)$ & $0.024(0.465)$ \\
\hline Circulatory & $0.009(0.911)$ & $0.014(1.268)$ \\
\hline Mental & $0.037(1.002)$ & $0.039(0.689)$ \\
\hline Mental, F0/F2/F6 & $0.004(0.272)$ & $0.003(0.146)$ \\
\hline Mental, F1 & $0.002(0.097)$ & $0.001(0.025)$ \\
\hline Mental, F3/F4 & $0.011(0.488)$ & $0.010(0.352)$ \\
\hline Mental, F5 & $0.010(0.392)$ & $0.016(0.399)$ \\
\hline Mental, F7/F8/F9 & $0.017(0.763)$ & $0.014(0.378)$ \\
\hline Individuals & 989,529 & 25,290 \\
\hline
\end{tabular}

For childhood outcomes observed later than age 0 , descriptives refer to individuals surviving up to the beginning of the age interval, since only those are used in the regressions. Standard deviation in hypotheses 
Table 2 Descriptive statistics for adult samples

\begin{tabular}{|c|c|c|}
\hline & Siblings & Twins \\
\hline Birth year & $1976.956(2.502)$ & $1977.020(2.589)$ \\
\hline Birth parity & $1.868(0.902)$ & $1.970(1.009)$ \\
\hline Gestational days & $281.071(12.369)$ & $263.532(17.158)$ \\
\hline Log birth weight & $8.150(0.167)$ & $7.852(0.214)$ \\
\hline Hospitalization & $0.324(3.367)$ & $0.362(3.508)$ \\
\hline Hospitalization, respiratory $(0 / 1)$ & 0.037 & 0.038 \\
\hline Hospitalization, neoplasms $(0 / 1)$ & 0.011 & 0.010 \\
\hline Hospitalization, endocrine, etc. $(0 / 1)$ & 0.018 & 0.017 \\
\hline Hospitalization, circulatory $(0 / 1)$ & 0.014 & 0.015 \\
\hline Hospitalization, mental $(0 / 1)$ & 0.036 & 0.036 \\
\hline Hospitalization, mental F0/F2/F6 (0/1) & 0.008 & 0.009 \\
\hline Hospitalization, mental F1 (0/1) & 0.016 & 0.015 \\
\hline Hospitalization, mental F3/F4 (0/1) & 0.020 & 0.020 \\
\hline Hospitalization, mental F5 (0/1) & 0.003 & 0.003 \\
\hline Hospitalization, mental F7/F8/F9 (0/1) & 0.003 & 0.003 \\
\hline Hospitalization days/year, respiratory & $0.018(0.772)$ & $0.017(0.286)$ \\
\hline Hospitalization days/year, neoplasms & $0.022(1.053)$ & $0.015(0.594)$ \\
\hline Hospitalization days/year, endocrine, etc. & $0.014(0.599)$ & $0.013(0.344)$ \\
\hline Hospitalization days/year, circulatory & $0.010(0.277)$ & $0.020(0.947)$ \\
\hline Hospitalization days/year, mental & $0.168(3.069)$ & $0.226(3.765)$ \\
\hline Hospitalization days/year, F0/F2/F6 (ICD10) & $0.093(2.509)$ & $0.130(2.923)$ \\
\hline Hospitalization days/year, F1 & $0.028(0.988)$ & $0.048(1.870)$ \\
\hline Hospitalization days/year, F3/F4 & $0.056(1.279)$ & $0.083(1.675)$ \\
\hline Hospitalization days/year, F5 & $0.016(0.733)$ & $0.018(0.665)$ \\
\hline Hospitalization days/year, F7/F8/F9 & $0.027(1.550)$ & $0.031(1.433)$ \\
\hline Sickness absence & $13.223(59.822)$ & $13.319(60.705)$ \\
\hline Sickness absence, respiratory $(0 / 1)$ & 0.005 & 0.003 \\
\hline Sickness absence, neoplasms $(0 / 1)$ & 0.002 & 0.002 \\
\hline Sickness absence, endocrine, etc. $(0 / 1)$ & 0.003 & 0.002 \\
\hline Sickness absence, circulatory $(0 / 1)$ & 0.002 & 0.002 \\
\hline Sickness absence, mental $(0 / 1)$ & 0.037 & 0.034 \\
\hline Sickness absence, mental F0/F2/F6 (0/1) & 0.004 & 0.005 \\
\hline Sickness absence, mental F1 (0/1) & 0.001 & 0.0005 \\
\hline Sickness absence, mental F3/F4 (0/1) & 0.027 & 0.024 \\
\hline Sickness absence, mental F5 (0/1) & 0.001 & 0.001 \\
\hline Sickness absence, mental F7/F8/F9 (0/1) & 0.007 & 0.007 \\
\hline Sickness absence, respiratory days & $0.172(5.176)$ & $0.125(4.075)$ \\
\hline Sickness absence, neoplasm days & $0.315(9.426)$ & $0.199(7.522)$ \\
\hline Sickness absence, endocrine, etc. days & $0.263(8.386)$ & $0.255(8.298)$ \\
\hline Sickness absence, circulatory days & $0.230(8.169)$ & $0.330(10.116)$ \\
\hline
\end{tabular}


Table 2 (continued)

\begin{tabular}{lll}
\hline & Siblings & Twins \\
\hline Sickness absence, mental days & $7.418(46.867)$ & $7.266(47.153)$ \\
Sickness absence, mental F0/F2/F6 days & $1.366(21.585)$ & $1.455(22.355)$ \\
Sickness absence, mental F1 days & $0.170(7.274)$ & $0.119(6.239)$ \\
Sickness absence, mental F3/F4 days & $4.350(34.015)$ & $3.895(32.507)$ \\
Sickness absence, mental F5 days & $0.186(7.461)$ & $0.168(7.344)$ \\
Sickness absence, mental F7/F8/F9 days & $2.227(27.934)$ & $2.322(28.418)$ \\
Individuals & 371,623 & 10,286 \\
\hline
\end{tabular}

Descriptives refer to individuals surviving up to the beginning of the age or time interval used, which means that those dying before 2011 are excluded when considering sickness absences. Standard deviation in hypotheses

birth year, birth month, parity, mother's birth year, mother's birth month, mother's education, and sex.

\subsection{Methods}

The aim of the analysis is to quantify the causal relationship between conditions experienced during the fetal stage, measured through birth weight, and health outcomes through childhood and into adulthood. Using birth weight as an indicator of the in utero experience of the individual is, however, problematic due to a range of factors. While we are able to control for the first key factor behind the individual's manifested birth weight and gestational length, individuals differ considerably in terms of their intrauterine growth rate. This is affected by both genetic and environmental factors, where in particular the former is problematic as mothers are predisposed to give birth to differently sized babies and where a lower size at birth not necessarily needs to be an indicator of having experienced in utero adversity. Another potential problem, as highlighted before, is that birth weight is related to some other unobserved factors that correlate with the birth weight, such as behavior. Our primary method of circumventing this problem is by examining a sample consisting of siblings. Hence, it will be assumed that differences in birth weight within siblings largely can be interpreted as resulting from physiological processes experienced by the fetus, as other factors relating to the mother that are known to influence birth weight, such as her physical characteristics and habits, are shared by siblings. In assessing the robustness of the sibling sample results, we also examine a sample of same-sex twins. In the case of single-placenta twins (constituting a majority of monozygotic (MZ) twins), birth weight differences may be viewed as randomly assigned, reflecting nutritional supply (Bryan 1992; Bajoria et al. 2001). Furthermore, MZ twins are characterized by identical DNA, whereas biological siblings (and dizygotic twins) only share 50\%. The sensitivity analyses focus on single-sex twins since, like many other studies, we have no information on zygosity or on whether twins have shared a single placenta. Relying on same-sex twin pairs thus increases the proportion of the sample that are MZ twins to about $60 \%$.

Our main empirical analysis is based on regressions of the following form.

$$
Y_{i j}=\alpha+\beta H_{i j}+X_{i j} \gamma+f_{j}+\varepsilon_{i j}
$$


Here, $i$ is the index for a child and $j$ for a sibling (or twin) pair. $Y$ is the health outcome observed after birth, such as the number of days of hospitalization at a certain age. $H$ is the natural logarithm of birth weight, and $X$ is the vector of individual control variables. These include controls for gestational length in days, as well as dummies for the birth year, calendar month of birth, birth parity, and sex of the child. They also include dummies for the birth year, calendar month of birth, and educational attainment of the mother. Standard errors are clustered at the family (i.e., mother) level.

Sibling (i.e., biological mother) fixed effects $\left(f_{j}\right)$ allow us to account for any factor that is specific to the family. If the mother is subject to different shocks at different pregnancies and these shocks only operate through effects on birth weight, results from these models can be interpreted as causal effects of birth weight. If effects also operate through other channels, the estimated effect of birth weight may be thought of as representing the effects of various shocks affecting the uterus of a certain mother at different times. In other words, effects do not necessarily mean the effect of birth weight per se. Using the fixed effects approach on twins, in the sensitivity analysis, we can potentially come closer to a causal effect of birth weight as we account for both genetic and environmental influences to a larger degree. In this case, birth weight cannot be thought of as representing shocks to the entire in utero environment, since both twins share the same environment.

\section{Results}

Throughout the "Results" section, we focus on two types of specifications. Our study sample, consisting of biological siblings, is analyzed by means of ordinary least square (OLS) regressions, with and without sibling fixed effects, the former being referred to as our "naïve" estimates.

\subsection{Childhood and adolescence hospitalizations}

We begin our analysis by considering short- and medium-term outcomes in the form of hospitalizations in childhood and adolescence. Results are shown in Table 3. Our naïve OLS specification (column A) reveals a strong relationship between birth weight and inpatient visits early in life. For hospitalizations during infancy (age 0), the coefficient is about -3.3 , implying that a $10 \%$ increase in birth weight is associated with 0.3 fewer days of hospital visits. It also implies that a one-standard deviation increase in the logarithm of birth weight ( $0.174 \mathrm{log}$ unit) reduces the number of days in inpatient care at the mean by about $41 \%$.

Accounting for sibling fixed effects (column B) produces a coefficient of -4.6 , which is, in fact, more strongly negative than the OLS estimate. At the mean, i.e., at 1.4 days of hospitalization at age zero, this translates into a reduction in inpatient days of $56 \%$ when log birth weight increases by a standard deviation. The fact that this effect is larger than its naïve OLS counterpart may potentially reflect parental responses, such as taking a lighter sibling more often to the hospital. However, in a likely scenario where birth weight is only a proxy for underlying health status, another explanation is possible: There are family-specific measurement errors involved when using birth 
Table 3 Inpatient visits (hospitalization) in childhood

A

B

No. of days/year

Age 0

$-3.337 * * *$

$-4.629 * * *$

(0.089)

(0.152)

Age 1

-0.368 ***

$-0.507 * * *$

(0.043)

(0.082)

Ages 2-5

$-0.134 * * *$

$-0.218^{* * *}$

Ages 6-12

(0.025)

(0.040)

-0.047 ***

-0.093 ***

(0.014)

(0.027)

Ages 13-17

$-0.019$

0.015

(0.017)

(0.034)

Diagnoses

Perinatal, age 0

$-0.083 * * *$

$-0.131^{* * * *}$

(0.002)

(0.003)

Neoplasms, ages 0-17

$0.003 * * *$

$-0.000$

(0.001)

(0.001)

Respiratory, ages 0-17

$-0.015^{* * *}$

$-0.033 * * *$

(0.003)

(0.005)

Endocrine, etc., ages 0-17

$-0.021 * * *$

$-0.031^{* * *}$

(0.001)

(0.002)

Circulatory, ages 0-17

$-0.002 * * *$

$-0.004 * * *$

(0.001)

(0.001)

Mental, ages 0-17

$-0.021 * * *$

$-0.019 * * *$

(0.001)

(0.003)

Mental F0/F2/F6, ages 0-17

$-0.000$

0.000

(0.000)

(0.001)

Mental F0/F2/F6, ages 0-17

$-0.005 * * *$

0.003 **

(0.001)

(0.001)

Mental F0/F2/F6, ages 0-17

-0.002 ***

$-0.000$

(0.001)

(0.001)

Mental F0/F2/F6, ages 0-17

-0.007 ***

$-0.010 * * *$

(0.001)

(0.001)

Mental F0/F2/F6, ages 0-17

$-0.010 * * *$

$-0.015^{* * * *}$

(0.001)

(0.001)

No. of days/year, diagnoses

Perinatal, age 0

$-2.457 * * *$
$(0.070)$
$0.020 * * *$
$(0.007)$
$-0.053 * * *$
$(0.011)$

$-3.361 * * *$

(0.115)

0.013

(0.011)

$-0.077^{* * * *}$

(0.021) 
Table 3 (continued)

\begin{tabular}{lll}
\hline & $\mathrm{A}$ & $\mathrm{B}$ \\
\hline Endocrine, etc., ages 0-17 & $-0.022^{* * *}$ & $-0.036^{* * * *}$ \\
Circulatory, ages 0-17 & $(0.004)$ & $(0.010)$ \\
Mental, ages 0-17 & $-0.029^{*}$ & $-0.083^{* * *}$ \\
Mental F0/F2/F6, ages 0-17 & $(0.016)$ & $(0.031)$ \\
Mental F0/F2/F6, ages 0-17 & $-0.027^{* * *}$ & $-0.027^{*}$ \\
& $(0.010)$ & $(0.015)$ \\
Mental F0/F2/F6, ages 0-17 & 0.001 & 0.000 \\
Mental F0/F2/F6, ages 0-17 & $(0.002)$ & $(0.004)$ \\
& $-0.002^{* * *}$ & 0.001 \\
Mental F0/F2/F6, ages 0-17 & $(0.001)$ & $(0.001)$ \\
& 0.003 & 0.004 \\
& $(0.005)$ & $(0.005)$ \\
& $-0.010^{*}$ & $-0.018^{*}$
\end{tabular}

*Significance at the $10 \%$ level

**Significance at the $5 \%$ level

****Significance at the $1 \%$ level

Controls include fixed effects for birth year, birth month, parity, gestational age, mother's birth year, mother's birth month, mother's education, and sex. Regressions were clustered at the mother level. Model A is an OLS model based on the sibling sample, and model B adds sibling fixed effects

weight to indicate health, and these get canceled out when applying the sibling fixed effects. ${ }^{3}$

Birth weight is also related to inpatient visits after the first year of life, albeit with an effect of a substantially smaller magnitude, in absolute as well as in relative terms. The naïve OLS specification (column A) suggests that an increase in birth weight is associated with an effect on days of hospitalization which decreases as the individual enters late childhood and adolescence. More specifically, at age one, a one-standard deviation increase in log birth weight is linked to $12 \%$ fewer hospital days at the mean. The corresponding figures at ages 2-5, 6-12, and 13-16 are 8.3, 4.4, and 1.6\%, respectively. Model $\mathrm{B}$, estimated with sibling fixed effects and thus taking into account everything that is shared between siblings, tends to produce stronger effects, but the same patterns remain. With the exception of ages 13-16, all effects are statistically significant, suggesting a gradually decreasing influence from birth weight as the individual ages, both in relative and in absolute terms.

We next turn to examine the relationship between birth weight and cause-specific morbidity, also presented in Table 3. We examine each respective diagnosis category both in terms of whether any hospitalization spell is experienced and in terms of the mean annual number of days of hospitalization. Starting with the naïve OLS estimates

\footnotetext{
${ }^{3}$ A derivation of this result is provided in the Appendix.
} 
in column A, hospitalization due to perinatal conditions is only examined during infancy, and the results for the number of days per year suggest that this type of hospitalization is the main driver of the total days of hospitalization due to any cause. More specifically, the point estimate of -2.5 amounts to almost $75 \%$ of the overall effect at age zero (-3.4). Both effects for perinatal conditions are furthermore statistically significant as well as quantitatively meaningful in relative terms. A one-standard deviation increase in log birth weight translates to a $31 \%$ lower probability at the mean of being hospitalized due to perinatal condition, whereas the corresponding effect for the number of days of hospitalization amounts to $72 \%$. Again, the sibling fixed effects estimates in column B display effects that are magnified in size. Indeed, a one-standard deviation increase in $\log$ birth weight results in an almost $100 \%$ decrease in the predicted number of days of hospitalization due to perinatal conditions at the mean.

Turning to other causes of morbidity during childhood and adolescence (ages 0-17), the results from both the naïve and the sibling fixed effects estimates show statistically significant results for all major diagnosis types with the exception of neoplasms. Thus, birth weight is linked to respiratory disease and endocrine and circulatory system disease as well as to mental illness. Evaluated at their respective means, birth weight most strongly influences the likelihood of any hospitalization due to endocrine and mental disease, with effects of a standard deviation increase in log birth weight ranging between 13 and 19\% for the naïve OLS specification and between 11 and 29\% for the sibling fixed effects specification. For the effect for the mean number of days of hospitalization due to each respective disease type, statistically significant and expected effects are again found throughout, except again for neoplasms. Moreover, the effects are larger in quantitative terms, with effects ranging from a $13 \%$ reduction in the mean days of hospitalization due to mental illness as a result of a one-standard deviation increase in log birth weight to a $56 \%$ decrease due to circulatory disease. Turning to the sibling fixed effects results, in column B, with the exception of mental disease, results are again amplified. This particularly applies to the estimate for circulatory disease morbidity, which at the mean translates to a $160 \%$ reduction in the number of days of hospitalization per standard deviation increase in log birth weight.

\subsection{Adult hospitalizations}

In Table 4, we show results for hospitalizations in adulthood, between the age of 18 and 30, organized in the same fashion as earlier tables. Starting with the estimate for the relationship between birth weight and the mean number of days of hospitalization, remembering the disappearance of the relationship between birth weight and hospitalization over the course of childhood and adolescence, the estimates both with and without sibling fixed effects are interesting as they suggest a reemergence of the relationship during adulthood. More specifically, the size of the effects is similar to the results found for ages $2-5$. In relative terms, during adulthood, a one-standard deviation increase in log birth weight results in an 8 or $12 \%$ decrease in the mean days of hospitalization at the mean according to the naïve and sibling fixed effects models, respectively.

Turning to the estimates of the cause-specific effects, clearer differences than for the childhood estimates are found when comparing the naïve and the sibling fixed effects models. In column A and for the likelihood of being hospitalized for a particular type of 
Table 4 Inpatient visits (hospitalization) in adulthood (ages 18-30)

\begin{tabular}{|c|c|c|}
\hline & A & B \\
\hline No. of days/year & $\begin{array}{l}-0.157 * * * \\
(0.041)\end{array}$ & $\begin{array}{l}-0.240^{* * * *} \\
(0.079)\end{array}$ \\
\hline \multicolumn{3}{|l|}{ Diagnoses } \\
\hline Neoplasms & $\begin{array}{l}0.004 * * * \\
(0.001)\end{array}$ & $\begin{array}{l}-0.000 \\
(0.002)\end{array}$ \\
\hline Respiratory & $\begin{array}{l}-0.005 * * \\
(0.002)\end{array}$ & $\begin{array}{l}-0.000 \\
(0.004)\end{array}$ \\
\hline Endocrine, etc. & $\begin{array}{l}-0.001 \\
(0.002)\end{array}$ & $\begin{array}{l}-0.002 \\
(0.003)\end{array}$ \\
\hline Circulatory & $\begin{array}{l}-0.003 * * \\
(0.001)\end{array}$ & $\begin{array}{l}-0.003 \\
(0.003)\end{array}$ \\
\hline Mental & $\begin{array}{l}-0.023 * * * \\
(0.002)\end{array}$ & $\begin{array}{l}-0.019^{\text {*** }} \\
(0.004)\end{array}$ \\
\hline Mental F0/F2/F6 & $\begin{array}{l}-0.005^{* * *} \\
(0.001)\end{array}$ & $\begin{array}{l}-0.004 * * \\
(0.002)\end{array}$ \\
\hline Mental F0/F2/F6 & $\begin{array}{l}-0.014 * * * \\
(0.002)\end{array}$ & $\begin{array}{l}-0.006^{*} \\
(0.003)\end{array}$ \\
\hline Mental F0/F2/F6 & $\begin{array}{l}-0.010^{* * * *} \\
(0.002)\end{array}$ & $\begin{array}{l}-0.008^{* *} \\
(0.003)\end{array}$ \\
\hline Mental F0/F2/F6 & $\begin{array}{l}-0.000 \\
(0.001)\end{array}$ & $\begin{array}{l}-0.001 \\
(0.001)\end{array}$ \\
\hline Mental F0/F2/F6 & $\begin{array}{l}-0.004 * * * \\
(0.001)\end{array}$ & $\begin{array}{l}-0.004^{* * *} \\
(0.001)\end{array}$ \\
\hline \multicolumn{3}{|c|}{ No. of days/year, diagnoses } \\
\hline Neoplasms & $\begin{array}{l}-0.021 \\
(0.013)\end{array}$ & $\begin{array}{l}-0.011 \\
(0.024)\end{array}$ \\
\hline Respiratory & $\begin{array}{l}-0.037 * * * \\
(0.010)\end{array}$ & $\begin{array}{l}-0.022 \\
(0.018)\end{array}$ \\
\hline Endocrine, etc. & $\begin{array}{l}-0.024^{* * * *} \\
(0.007)\end{array}$ & $\begin{array}{l}-0.031 * * \\
(0.014)\end{array}$ \\
\hline Circulatory & $\begin{array}{l}-0.008^{* *} \\
(0.003)\end{array}$ & $\begin{array}{l}-0.009 \\
(0.007)\end{array}$ \\
\hline Mental & $\begin{array}{l}-0.106^{* * * *} \\
(0.038)\end{array}$ & $\begin{array}{l}-0.211 * * * \\
(0.072)\end{array}$ \\
\hline Mental F0/F2/F6 & $\begin{array}{l}-0.051 \\
(0.031)\end{array}$ & $\begin{array}{l}-0.084 \\
(0.059)\end{array}$ \\
\hline Mental F0/F2/F6 & $\begin{array}{l}-0.031 * * \\
(0.012)\end{array}$ & $\begin{array}{l}-0.025 \\
(0.024)\end{array}$ \\
\hline Mental F0/F2/F6 & $\begin{array}{l}-0.035^{* *} \\
(0.016)\end{array}$ & $\begin{array}{l}-0.057 * \\
(0.030)\end{array}$ \\
\hline
\end{tabular}


Table 4 (continued)

A

\begin{tabular}{llc}
\hline Mental F0/F2/F6 & 0.004 & -0.011 \\
& $(0.009)$ & $(0.017)$ \\
Mental F0/F2/F6 & $-0.044 * *$ & -0.039 \\
& $(0.019)$ & $(0.037)$ \\
\hline
\end{tabular}

*Significance at the $10 \%$ level

**Significance at the $5 \%$ level

***Significance at the $1 \%$ level

Controls include fixed effects for birth year, birth month, parity, gestational age, mother's birth year, mother's birth month, mother's education, and sex. Regressions were clustered at the mother level. Model A is an OLS model based on the sibling sample, and model B adds sibling fixed effects

illness, all estimates except for endocrine disease are statistically significant, something which only applies to mental disease in column B. Consequently, the only relationship between birth weight and the likelihood of hospitalization that is robust to controlling for family characteristics is mental disease, where the sibling fixed effects model suggests a $9 \%$ decrease as a result of a one-standard deviation increase in log birth weight. Likewise, when it comes to the influence on the mean days of annual hospitalization, does the effect on mental illness remain in column B The size of the effect is also considerable in the sibling fixed effects model, amounting to a $21 \%$ decrease in the predicted annual days of hospitalization per standard deviation increase in $\log$ birth weight.

Considering the consistent importance of mental illness as it drives the effect in adulthood, we proceed to investigate whether the effect is dominated by a particular type of mental disorder. The sibling fixed effects estimates in column B suggest that birth weight significantly influences the likelihood of hospitalization in all types of mental illness, except for behavioral syndromes associated with physiological disturbances and physical factors, dominated by eating disorders. In relative terms, the effect is the greatest for the ICD10 categories F7-F9, including ADHD disorders and intellectual disabilities, amounting to a $22 \%$ reduction per one-standard deviation increase in log birth weight. Effects are estimated with less precision when it comes to how birth weight is linked to the mean days of hospitalization. Indeed, according to the sibling fixed effects model in column B, such a link can only be established for mood-, anxiety-, and stress-related disorders, with a one-standard deviation increase in log birth weight resulting in a $17 \%$ decrease in the mean annual days of hospitalization in adulthood.

\subsection{Adult sickness absences}

Lastly, we consider effects on sickness absences in adulthood, observed during 2011, when the study sample is between the ages of 29 and 38. Given the larger variation in this outcome than in hospitalizations, potential effects of early-life health may be easier to detect; on the other hand, if sickness absences are a less severe outcome than hospitalizations, effects may also be weaker and less significant. Results are shown in Table 5, providing qualitatively similar results as those already observed for adulthood 
Table 5 Sickness absences in adulthood (year 2011)

\begin{tabular}{|c|c|c|}
\hline & A & B \\
\hline No. of days & $\begin{array}{l}-9.015 * * * \\
(0.739)\end{array}$ & $\begin{array}{l}-12.111^{* * * *} \\
(1.368)\end{array}$ \\
\hline \multicolumn{3}{|l|}{ Diagnoses } \\
\hline Neoplasms & $\begin{array}{l}0.001 \\
(0.001)\end{array}$ & $\begin{array}{l}0.002 \\
(0.001)\end{array}$ \\
\hline Respiratory & $\begin{array}{l}-0.000 \\
(0.001)\end{array}$ & $\begin{array}{l}-0.001 \\
(0.002)\end{array}$ \\
\hline Endocrine, etc. & $\begin{array}{l}0.001 \\
(0.001)\end{array}$ & $\begin{array}{l}-0.000 \\
(0.001)\end{array}$ \\
\hline Circulatory & $\begin{array}{c}-0.000 \\
(0.000)\end{array}$ & $\begin{array}{l}0.000 \\
(0.001)\end{array}$ \\
\hline Mental & $\begin{array}{l}-0.017 * * * \\
(0.002)\end{array}$ & $\begin{array}{l}-0.025^{* * *} \\
(0.004)\end{array}$ \\
\hline Mental F0/F2/F6 & $\begin{array}{l}-0.003^{* * *} \\
(0.001)\end{array}$ & $\begin{array}{c}-0.002 \\
(0.002)\end{array}$ \\
\hline Mental F0/F2/F6 & $\begin{array}{l}-0.001^{*} \\
(0.000)\end{array}$ & $\begin{array}{l}0.001 \\
(0.001)\end{array}$ \\
\hline Mental F0/F2/F6 & $\begin{array}{l}-0.006^{* * *} \\
(0.002)\end{array}$ & $\begin{array}{l}-0.007 * \\
(0.004)\end{array}$ \\
\hline Mental F0/F2/F6 & $\begin{array}{l}-0.000 \\
(0.000)\end{array}$ & $\begin{array}{l}-0.001 \\
(0.001)\end{array}$ \\
\hline Mental F0/F2/F6 & $\begin{array}{l}-0.009 * * * \\
(0.001)\end{array}$ & $\begin{array}{l}-0.017 * * * \\
(0.002)\end{array}$ \\
\hline \multicolumn{3}{|c|}{ No. of days, diagnoses } \\
\hline Tumor & $\begin{array}{l}0.108 \\
(0.117)\end{array}$ & $\begin{array}{l}0.146 \\
(0.223)\end{array}$ \\
\hline Respiratory & $\begin{array}{l}0.013 \\
(0.064)\end{array}$ & $\begin{array}{l}0.070 \\
(0.122)\end{array}$ \\
\hline Endocrine, etc. & $\begin{array}{l}-0.078 \\
(0.104)\end{array}$ & $\begin{array}{l}-0.087 \\
(0.198)\end{array}$ \\
\hline Circulatory & $\begin{array}{l}-0.208 * * \\
(0.101)\end{array}$ & $\begin{array}{c}-0.235 \\
(0.194)\end{array}$ \\
\hline Mental & $\begin{array}{l}-5.213^{* * * *} \\
(0.580)\end{array}$ & $\begin{array}{l}-7.912 * * * \\
(1.078)\end{array}$ \\
\hline Mental F0/F2/F6 & $\begin{array}{l}-1.023^{* * * *} \\
(0.268)\end{array}$ & $\begin{array}{c}-0.700 \\
(0.505)\end{array}$ \\
\hline Mental F0/F2/F6 & $\begin{array}{l}-0.123 \\
(0.090)\end{array}$ & $\begin{array}{l}0.076 \\
(0.171)\end{array}$ \\
\hline Mental F0/F2/F6 & $\begin{array}{l}-1.231 * * * \\
(0.421)\end{array}$ & $\begin{array}{l}-1.477 * \\
(0.793)\end{array}$ \\
\hline
\end{tabular}


Table 5 (continued)

\begin{tabular}{llc}
\hline & A & B \\
\hline Mental F0/F2/F6 & -0.069 & -0.183 \\
& $(0.093)$ & $(0.178)$ \\
Mental F0/F2/F6 & $-3.163 * * *$ & $-5.887 * * *$ \\
& $(0.346)$ & $(0.643)$ \\
\hline
\end{tabular}

*Significance at the $10 \%$ level

**Significance at the $5 \%$ level

***Significance at the $1 \%$ level

Controls include fixed effects for birth year, birth month, parity, gestational age, mother's birth year, mother's birth month, mother's education, and sex. Regressions were clustered at the mother level. Model A is an OLS model based on the sibling sample, and model B adds sibling fixed effects

hospitalization in terms of which underlying diagnoses are dominating. For the total number of days, the naïve OLS estimates (column A) are once again indicating that any possible bias resulting from this estimation method underestimates the link between birth weight and later-life health, as estimates are smaller than the ones based on sibling fixed effects. According to the sibling fixed effects estimates (column B), a one-standard deviation increase in log birth weight reduces the predicted number of sick days by about 2 per year, corresponding to about $15 \%$ of the mean number of sickness days per year.

We next consider the incidence of sickness absence due to different diagnoses. The naïve OLS (column A) and sibling fixed effects (column B) specifications again suggest that the link between birth weight and early-adulthood health is largely driven by mental conditions. This is suggested both by the estimates for whether the individual experiences a sickness absence spell due to a mental condition and by those for the number of days of sickness absence. More specifically, a one-standard deviation increase in log birth weight is, according to the sibling fixed effects model, linked to an 11 and $18 \%$ reduction in aforementioned outcomes, respectively. Again, the results suggest that it is morbidity due to the mental disease groups that include $A D H D$ disorders and intellectual disabilities as well as mood-, anxiety-, and stress-related disorders that can be confidently linked to birth weight, with the relative effect being particularly strong in terms of the former category.

\subsection{Heterogeneous effects by maternal education}

Up to this point, the results have painted a picture of a relationship between birth weight and morbidity that changes across the life course, both in terms of its strength and in terms of the type of health problems that result from being subject to impaired fetal growth. Previous research has suggested that the effects of early-life insults may be modified by various forms of parental investments. The most prevalent hypothesis suggests that it is especially the more highly educated and financially well-off parents who have the ability to identify ways to counteract the consequences of in utero adversity as well as the resources to implement such measures. Consequently, we next examine whether indications of smaller or nonexistent responses to birth weight are 
found among children of highly educated mothers, presented through sibling fixed effects models in Table 6.

Column A displays the results for children of mothers with primary or secondary education, with column B containing the results for children of university-educated mothers. Looking at the estimates for the link between birth weight and hospitalization during infancy, we see a larger effect among children of mothers with less education-consistent with the hypothesis that parental resources moderate the relationship. Furthermore, the estimates are statistically significantly different. Considering the remaining estimates, results fail to support the hypothesis that parental resources systematically moderate the relationship between birth weight and health through adulthood. Not only are the effects across the educational groups statistically indistinguishable from each other but the effects among children of highly educated mothers are larger for several age groups, clearly inconsistent with the hypothesis that parental resources or investments matter. A similarly inconsistent story emerges when examining cause-specific morbidity (not shown, available at request). Thus, with the exception of health in infancy, more well-off families do not seem to be able to compensate for poor neonatal health, a finding pointing at the importance of improving nutrition and health already around the time of birth, rather than trying to implement offsetting policies.

Table 6 Stratification by mother's education

\begin{tabular}{cll}
\hline & A & B \\
\hline Hospitalization days/year & & $-4.155^{* * *}$ \\
No. of days, age 0 & $-4.844^{* * * *}$ & $(0.247)$ \\
No. of days, age 1 & $(0.191)$ & $-0.496^{* * *}$ \\
& $-0.511^{* * *}$ & $(0.155)$ \\
No. of days, ages 2-5 & $(0.093)$ & $-0.300^{* * *}$ \\
& $-0.171^{* * * *}$ & $(0.068)$ \\
No. of days, ages 6-12 & $(0.048)$ & $-0.136^{* * *}$ \\
No. of days, ages 13-17 & $-0.072^{* * *}$ & $(0.038)$ \\
& $(0.036)$ & $-0.089 * *$ \\
No. of days, ages 18-30 & 0.075 & $(0.045)$ \\
& $(0.046)$ & $-0.368^{* * *}$ \\
Sickness absence days, 2011 & $-0.166^{*}$ & $(0.127)$ \\
& $(0.100)$ & $-11.249 * * *$ \\
\hline
\end{tabular}

*Significance at the $10 \%$ level

**Significance at the $5 \%$ level

****Significance at the $1 \%$ level

Controls include fixed effects for birth year, birth month, parity, gestational age, mother's birth year, mother's birth month, mother's education, and sex. Sibling fixed effect regressions were clustered at the mother level. Model A is based on individuals whose mother has less primary or secondary education only, whereas model $\mathrm{B}$ is based on individuals whose mother has tertiary education 


\subsection{Nonlinear effects by birth weight}

Table 7 shows the results from sibling fixed effects models for the mean annual days of hospitalization in the different age groups, where the effect of birth weight is allowed to vary across its distribution through the introduction of splines at 2000, 2500, and $3000 \mathrm{~g}$. More specifically, the analysis is performed by allowing the effect of birth weight to differ across the different categories of birth weight, while also controlling for the interval itself. Similar to the main analysis, the largest effects are found during infancy, with the overall effect previously encountered being similar to that in the birth weight interval 2500-3000 g. More specifically, within this interval, the point estimate amounts to -4.945 , to be compared to -4.629 in the main analysis, something which may be expected since this represents a common range in terms of birth weight. The results also suggest that an individual at the lower end of the birth weight distribution is particularly disadvantaged during infancy, with large and statistically significant effects for both the 2000-2500 $\mathrm{g}$ and the $2000 \mathrm{~g}$ and under birth weight interval. Lastly, the health effect among heavier babies (above $3000 \mathrm{~g}$ ) is substantially smaller, but still significant and negative.

The remaining age groups fail to produce a consistent pattern across the birth weight spectrums, however with statistically significant effects most commonly being found in the 2500-3000 g group. Throughout all hospitalization outcomes at ages one and above, the results fail to suggest that those with birth weights below $2000 \mathrm{~g}$ are disproportionately disadvantaged in terms of health. The same applies to sickness absence where, however, large effects are found for the intervals 2000$2500 \mathrm{~g}$ and $3000 \mathrm{~g}$ and above, whereas weighing $2500 \mathrm{~g}$ is not significantly worse than weighing just below $3000 \mathrm{~g}$. In conclusion, the nonlinear effects fail to suggest that the results obtained from the main analysis were driven by individuals at the extreme ends of the birth weight distribution. These conclusions are also supported by estimates obtained while limiting the sample to individuals within \pm two standard deviations around the mean in terms of their birth weight (not shown, available at request).

\subsection{Same-sex twins}

Clearly, there are characteristics which a sibling fixed effects approach may fail to take into account, such as genetic factors not shared between siblings or within-mother variation in the fetal environment. While associated with certain weaknesses pertaining to the external validity of examining twins, the advantage of analyzing MZ twins is that shared influence of genes is completely canceled out, as well as other factors so that birth weight is plausibly being exogenously assigned. While we do not know whether the observed twins in our data are monozygotic or dizygotic, restricting the sample to same-sex twins increases the proportion of the sample that is monozygotic. Another caveat relates to the statistical power of the estimates. Since the study population of same-sex twin pairs only amounts to 8800 in childhood and 3700 in adulthood, respectively, we only look at the link between birth weight and the mean days of annual hospitalization across age groups, and not at separate diagnoses; results are displayed in Table 8 . 
Table 7 Nonlinearity: knots at 2000, 2500, and $3000 \mathrm{~g}$

\begin{tabular}{|c|c|}
\hline \multicolumn{2}{|l|}{ No. of days, age 0} \\
\hline Effect below $2000 \mathrm{~g}$ & $\begin{array}{c}-17.799 * * * \\
(2.044)\end{array}$ \\
\hline Effect between 2000 and $2500 \mathrm{~g}$ & $\begin{array}{c}-19.181 * * * \\
(1.412)\end{array}$ \\
\hline Effect between 2500 and $3000 \mathrm{~g}$ & $\begin{array}{c}-4.945 * * * \\
(0.669)\end{array}$ \\
\hline Effect above $3000 \mathrm{~g}$ & $\begin{array}{c}-1.049 * * * \\
(0.116)\end{array}$ \\
\hline \multicolumn{2}{|l|}{ No. of days, age 1} \\
\hline Effect below $2000 \mathrm{~g}$ & $\begin{array}{l}-0.148 \\
(0.866)\end{array}$ \\
\hline Effect between 2000 and $2500 \mathrm{~g}$ & $\begin{array}{l}-0.730 \\
(0.799)\end{array}$ \\
\hline Effect between 2500 and $3000 \mathrm{~g}$ & $\begin{array}{c}-0.991 * * \\
(0.412)\end{array}$ \\
\hline Effect above $3000 \mathrm{~g}$ & $\begin{array}{c}-0.338 * * * \\
(0.079)\end{array}$ \\
\hline \multicolumn{2}{|l|}{ No. of days/year, ages $2-5$} \\
\hline Effect below $2000 \mathrm{~g}$ & $\begin{array}{l}-0.205 \\
(0.329)\end{array}$ \\
\hline Effect between 2000 and $2500 \mathrm{~g}$ & $\begin{array}{c}0.162 \\
(0.413)\end{array}$ \\
\hline Effect between 2500 and $3000 \mathrm{~g}$ & $\begin{array}{c}-0.543^{*} \\
(0.278)\end{array}$ \\
\hline Effect above $3000 \mathrm{~g}$ & $\begin{array}{c}-0.162 * * * \\
(0.040)\end{array}$ \\
\hline \multicolumn{2}{|l|}{ No. of days/year, ages 6-12 } \\
\hline Effect below $2000 \mathrm{~g}$ & $\begin{array}{c}0.007 \\
(0.110)\end{array}$ \\
\hline Effect between 2000 and $2500 \mathrm{~g}$ & $\begin{array}{l}-0.197 \\
(0.241)\end{array}$ \\
\hline Effect between 2500 and $3000 \mathrm{~g}$ & $\begin{array}{l}-0.090 \\
(0.171)\end{array}$ \\
\hline Effect above $3000 \mathrm{~g}$ & $\begin{array}{c}-0.066^{* *} \\
(0.032)\end{array}$ \\
\hline \multicolumn{2}{|l|}{ No. of days/year, ages $13-17$} \\
\hline Effect below $2000 \mathrm{~g}$ & $\begin{array}{c}0.177 \\
(0.154)\end{array}$ \\
\hline Effect between 2000 and $2500 \mathrm{~g}$ & $\begin{array}{l}-0.126 \\
(0.381)\end{array}$ \\
\hline Effect between 2500 and $3000 \mathrm{~g}$ & $\begin{array}{c}-0.281^{*} \\
(0.168)\end{array}$ \\
\hline
\end{tabular}


Table 7 (continued)

Effect above $3000 \mathrm{~g}$

No. of days/year, ages 18-30

Effect below $2000 \mathrm{~g}$

Effect between 2000 and $2500 \mathrm{~g}$

Effect between 2500 and $3000 \mathrm{~g}$

Effect above $3000 \mathrm{~g}$

No. of sickness absence days in 2011

Effect below $2000 \mathrm{~g}$

Effect between 2000 and $2500 \mathrm{~g}$

Effect between 2500 and $3000 \mathrm{~g}$

Effect above $3000 \mathrm{~g}$

\footnotetext{
*Significance at the $10 \%$ level

**Significance at the $5 \%$ level

***Significance at the $1 \%$ level
}

Sibling fixed effect models. Controls include fixed effects for birth year, birth month, parity, gestational age, mother's birth year, mother's birth month, mother's education, sex, and dummies for being in the different birth weight intervals. Regressions were clustered at the mother level

As expected, the parameters are estimated with less precision than in the main analysis. Indeed, only the point estimate for mean days of hospitalization during infancy is statistically significant in a model with sibling fixed effects, with an estimate that is attenuated somewhat compared to the main analysis. The result indicates that the additional unobserved heterogeneity that is canceled out through the twin fixed effect models reduces the point estimate from about -4.6 to -3.8 . Despite this, the size of the effect remains substantial, further reinforcing the notion of a causal impact from birth weight on health during infancy.

While the remaining estimates fail to be statistically significant, their sign is expected and their sizes remain rather similar to those in the main analysis, at least throughout childhood. In adulthood, the twin estimate $(-0.75)$ is considerably larger than the sibling estimate $(-0.24)$, whereas the reverse applies to sickness absence ( -12 for siblings, -2 for twins). Thus, while the lack of precision of the twin estimates is unfortunate, the identical pattern is observed across study samples, with an effect from birth weight on health which gradually diminishes throughout childhood and adolescence, only to reappear in adulthood. 
Table 8 Same-sex twin pairs

\begin{tabular}{lc} 
Hospitalization days/year & $-3.769^{* * *}$ \\
No. of days, age 0 & $(0.848)$ \\
No. of days, age 1 & -0.345 \\
No. of days, ages 2-5 & $(0.277)$ \\
No. of days, ages 6-12 & -0.055 \\
& $(0.124)$ \\
No. of days, ages 13-17 & -0.148 \\
& $(0.104)$ \\
No. of days, ages 18-30 & -0.004 \\
Sickness absence days, 2011 & $(0.110)$ \\
& -0.748 \\
& $(0.519)$ \\
\hline
\end{tabular}

*Significance at the $10 \%$ level

** Significance at the $5 \%$ level

*** Significance at the $1 \%$ level

Twin fixed effect models. Controls include birth year, birth month, parity, gestational age, mother's birth year, mother's birth month, mother's education, gestational age, and sex. Regressions were clustered at the mother level. Estimates are based on 8835 pairs of same-sex twins in childhood, with the corresponding number being 3708 in adulthood

\section{Conclusion}

Using full-population administrative data, this article studied the impact of the individual's in utero experience, measured by birth weight, on health outcomes measured throughout childhood and adolescence and into adulthood, measured through hospitalization and sickness absence. In an attempt to sort out the effects of parental circumstances and behaviors as well as genetic factors, our analysis focused on comparing the outcomes of siblings and twins. When interpreting the results, caveats associated with relying on birth weight as an indicator of in utero circumstances need to be acknowledged. Fetuses experience different growth processes that are not necessarily due to in utero insults but instead the result of, for example, the mother's physical stature. Therefore, interpreting a low birth weight as synonymous with adversity is problematic. In this study, we claim to largely control for such maternal-specific processes through the use of sibling and twin fixed effect models, while we remain confident that the most significant sources of bias are removed.

In general, our estimates suggest largely similar effects when comparing naïve OLS and sibling fixed effects estimates, indicating that the selection on unobservable characteristics at the sibling level is small. While the twin fixed effect estimates are associated with important advantages, including a greater control 
over the influence of genes, the smaller sample size clearly limits statistical power, and the degree to which obtained results can be extrapolated to a broader population may be questioned. Nevertheless, our results based on twin comparisons are broadly in line with those based on siblings.

Overall, the results from our specifications, examining the influence of birth weight on health throughout childhood and adolescence and into early adulthood, suggest a U-shaped pattern. More specifically, with sizeable effects during the first years of life in absolute as well as in relative terms, the influence diminishes in importance during later childhood and adolescence. In adulthood, past the age of 18 , the influence again becomes stronger, with broadly similar conclusions regarding both hospitalizations and sickness absences. Indeed, our ability to follow individuals from birth until their adult ages, contrasting the size of the effect across the parts of the life course observed, represents one of this study's key contributions.

During childhood and adolescence, the health penalty linked to a lower birth weight is represented by a range of disease types, suggesting a generally worse health rather than one single disease mechanism. Indeed, all examined disease types with the exception of cancer are found to be linked to a lower birth weight. In early adulthood, a different pattern is found, with a strong emphasis on mental conditions. The effect on this outcome is quite substantial, and mental illness almost entirely drives the effect of birth weight on the number of days of hospitalization in adulthood. Albeit not quite as dramatic, a similar story emerges for sickness absence. These are important findings, as they provide new empirical evidence regarding the dynamic nature of the relationship between the in utero experience and postnatal health.

Industrialized countries currently face financial challenges due to rising costs of health care and sickness absences. Here, one key challenge lies in the increasing rates of disability due to mental problems (Prins 2010). Having documented the role of birth weight, we believe our results have important policy implications, pointing at the potential benefit of programs such as WIC (the Special Supplemental Nutrition Program for Women, Infants, and Children) in the USA, which provide nutritional counseling and supplemental food to pregnant women. Programs like this are likely to reduce costs not only due to physical health problems among children but also due to mental health problems in the longer run.

Acknowledgements Jonas Helgertz and Anton Nilsson acknowledge the support and financial assistance from the Centre for Economic Demography, Lund University. Anton Nilsson also acknowledges a Wallander grant from the Jan Wallander and Tom Hedelius Foundation. We also thank the anonymous reviewers for the helpful comments and suggestions.

Funding This study was funded by the Centre for Economic Demography, Lund University (Swedish Research Council grant number 2006-79) and a Wallander grant from the Jan Wallander and Tom Hedelius Foundation.

\section{Compliance with ethical standards}

Conflict of interest The authors declare that they have no conflict of interest. 
Open Access This article is distributed under the terms of the Creative Commons Attribution 4.0 International License (http://creativecommons.org/licenses/by/4.0/), which permits unrestricted use, distribution, and reproduction in any medium, provided you give appropriate credit to the original author(s) and the source, provide a link to the Creative Commons license, and indicate if changes were made.

\section{References}

Ajani JA, Song S, Hochster HS, Steinberg IB (2015) Cancer stem cells: the promise and the potential. Semin Oncol 42(2, S1):S3-S17

Almond D (2006) Is the 1918 influenza pandemic over? Long-term effects of in utero influenza exposure in the post-1940 US population. J Polit Econ 114:672-712

Almond D., Currie J. 2011. Human capital development before age five. In: Handbook of labor economics 4b: 1315-1486. Amsterdam, Netherlands: Elsevier

Almond D, Chay KY, Lee DS (2005) The costs of low birth weight. Q J Econ 120:1031-1082

Almond D, Edlund L, Palme M (2009) Chernobyl's subclinical legacy: prenatal exposure to radioactive fallout and school outcomes in Sweden. Q J Econ 124:1729-1772

Almond D., Edlund L., Li H., Zhang J. 2010. Long-term effects of early-life development: evidence from the 1959 to 1961 China famine. In: The economic consequences of demographic change in East Asia, NBEREASE 19: 321-345. Chicago, Il: Chicago University Press

Bajoria R, Sooranna SR, Ward S, D'Souza S, Hancock M (2001) Placental transport rather than maternal concentration of amino acids regulates fetal growth in monochorionic twins: implications for fetal origin hypothesis. Am J Obstet Gynecol 185:1239-1246

Barker DJP (1990) The fetal and infant origins of adult disease: the womb may be more important than the home. Br Med J 301:1111

Barker DJ (1995) Fetal origins of coronary heart disease. Br Med J 311:171-174

Barker D.J.P., Winter, P.D., Osmond, C., Margetts, B., \& Simmonds, S.J. 1889. Weight in infancy and death from ischaemic heart disease. Lancet

Bharadwaj, P, Lundborg, P., \& Rooth, D-O. 2018. Birth Weight in the Long Run. J Hum Resour 53:189-231

Black S, Devereux P, Salvanes K (2007) From the cradle to the labor market? The effect of birth weight on adult outcomes. Q J Econ 122:409-439

Bryan E (1992) Twins and higher order births: a guide to their nature and nurture. Edward Arnold, London, UK

Chen Y, Zhou L-A (2007) The long-term health and economic consequences of the 1959-1961 famine in China. J Health Econ 26:659-681

Clarke MF (2005) Self-renewal and solid-tumor stem cells. Biol Blood Marrow Transplant 11:14-16

Conley, D. Strully, K.W. 2012. Birth weight, infant mortality, and race: twin comparisons and genetic/ environmental inputs. Social Science \& Medicine, 75(12), 2446-2454

Duijts L (2012) Fetal and infant origins of asthma. Eur J Epidemiol 27:5-14

Eckel RH (1997) Obesity and heart disease. A statement for healthcare professionals from the nutrition committee, American Heart Association. Circulation 96:3248-3250

Field E, Robles O, Torero M (2009) Iodine deficiency and schooling attainment in Tanzania. Am Econ J: Appl Econ 1:140-169

Geva R, Eshel R, Leitner Y, Valevski AF, Harel S (2006) Neuropsychological outcome of children with intrauterine growth restriction: a 9-year prospective study. Pediatrics 118:91-100

Grundy SM, Benjamin IJ, Burke GL, Chait A, Eckel RH, Howard BV, Mitch W, Smith SC Jr, Sowers JR (2000) Diabetes and cardiovascular disease: a statement for healthcare professionals from the American Heart Association. Circulation 100(10):1134-1146

Hales CN, Barker DJ (1992) Type 2 (non-insulin-dependent) diabetes mellitus: the thrifty phenotype hypothesis. Diabetologia 35(7):595-601

Harding R, Maritz G (2012) Maternal and fetal origins of lung disease in adulthood. Semin Fetal Neonatal Med 17:67-72

Hilakivi-Clarke L, de Assis S (2006) Fetal origins of breast cancer. Trends Endocrinol Metab 17(9):340-348

Huxley R, Neil A, Collins R (2002) Unravelling the fetal origins hypothesis: is there really an inverse association between birthweight and subsequent blood pressure? Lancet 36:659-665

Huxley, R. Owen, C.G, Whincup, P.H, Cook, D.G, Rich-Edwards, J, Smith, G.D, \& Collins, R. 2007. Is birth weight a risk factor for ischemic heart disease in later life? Am J Clin Nutr 5(1), 1244-1250

Kanaka-Gantenbein C (2010) Fetal origins of adult diabetes. Ann N Y Acad Sci 1205:99-105 
Karlsson M, Nilsson T, Pichler S (2014) The impact of the 1918 Spanish flu epidemic on economic performance in Sweden: an investigation into the consequences of an extraordinary mortality shock. J Health Econ 36:1-19

Kelly E (2011) The scourge of Asian flu: in utero exposure to pandemic influenza and the development of a cohort of British children. J Hum Resour 46(4):669-694

Kindlund K, Thomsen SF, Stensballe LG, Skytthe A, Kyvik KO, Backer VB, Bisgaard H (2010) Birth weight and risk of asthma in 3-9-year-old twins: exploring the fetal origins hypothesis. Thorax 65:146-149

Marshall GM, Carter DR, Belamy BC, Tao Liu C, Mateos MK, Meyerowitz JG, Weiss WA (2014) The prenatal origins of cancer. Nat Rev 14:277-289

Martinussen M, Fischl B, Larsson HB, Skranes J, Kulseng S, Vangberg TR, Vik T, Brubakk AM, Haraldseth O, Dale AM (2005) Cerebral cortex thickness in 15-year-old adolescents with low birth weight measured by an automated MRI-based method. Brain 128:2588-2596

McEwen BS (2003) Early life influences on life-long patterns of behavior and health. Ment Retard Dev Disabil Res Rev 9:149-154

Myrskylä M, Mehta NK, Chang VW (2013) Early life exposure to the 1918 influenza pandemic and old-age mortality by cause of death. Am J Public Health 103:e83-e90

Oken E, Gillman MW (2003) Fetal origins of obesity. Obes Res 11(4):496-506

Oreopoulos P, Stabile M, Walld R, Roos LL (2008) Short-, medium-, and long-term consequences of poor infant health. J Hum Resour 43:88-138

Örtqvist AK, Lundholm C, Carlström E, Lichtenstein P, Cnattingus S, Almqvist C (2009) Familial factors do not confound the association between birth weight and childhood asthma. Pediatrics 124:e737-e743

Padmanabhan V, Cardoso RC, Puttabyatappa M (2016) Developmental programming, a pathway to disease. Endocrinology 157(4):1328-1340

Pettersson E, Sjölander A, Almqvist C, Anckarsäter H, D’Onofrio BM, Lichtenstein P, Larsson H (2015) Birth weight as an independent predictor of ADHD symptoms: a within-twin pair analysis. J Child Psychol Psychiatry 56:453-459

Poulsen P, Vaag AA, Kyvik KO, Møller Jensen D, Beck-Nielsen H (1997) Low birth weight is associated with NIDDM in discordant monozygotic and dizygotic twin pairs. Diabetologia 40:439-446

Prins R (2010) Sickness absence and disability: an international perspective. In: Handbook of work disability. Springer, New York, pp 3-14

Rooij SR, Wouters H, Yonker JE, Painter RC, Roseboom TJ (2010) Prenatal undernutrition and cognitive function in late adulthood. Proc Natl Acad Sci 107:16881-16886

Royer H (2009) Separated at girth: US twin estimates of the effects of birth weight. Am Econ J: Appl Econ 1: 49-85

Saldarriaga V (2015) Birth weight and early childhood physical health: evidence from a sample of Latin American twins. J Latin Am Caribb Econ Assoc 15:161-197

Schlotz W, Phillips DIW (2009) Fetal origins of mental health: evidence and mechanisms. Brain Behav Immun 23:905-916

Schlotz W, Jones A, Godfrey KM, Phillips DIW (2008) Effortful control mediates associations of fetal growth with hyperactivity and behavioural problems in 7- to 9-year-old children. J Child Psychol Psychiatry 49: 1228-1236

Scholte R., van den Berg G.J., Lindeboom M. 2012. Long-run effects of gestation during the Dutch hunger winter famine on labor market and hospitalization outcomes. IZA Discussion Paper 6307

Shukla S, Meeran SM (2014) Epigenetics of cancer stem cells: pathways and therapeutics. Biochim Biophys Acta 1840:3494-3502

Wiemels JL, Cazzaniga G, Daniotti M, Eden OB, Addison GM, Masera G, Saha V, Biondi A, Greaves MF (1999) Prenatal origin of acute lymphoblastic leukaemia in children. Lancet 354(9189):1499-1503

Xie, Z-X., Chou, S-Y., Liu, J-T. 2016. The short-run and long-run effects of birth weight: evidence from large samples of siblings and twins in Taiwan. Health Economics 